Apuntes del CENES

ISSN 0120-3053

Artículo de investigación

Volumen $35, \mathrm{~N}^{\circ} 61$

Enero - Junio 2016

Págs. 51-84

\title{
Análisis de la evolución de la inversión extranjera directa en el sector minero del carbón en Colombia de 2004 a 2013 *
}

\author{
Analysis of the evolution of foreign \\ direct investment in the coal mining \\ sector in Colombia from 2002 to 2013 \\ Análise da evolução de investimento \\ estrangeiro directo no setor de \\ mineração de carvão na Colômbia a \\ partir de 2004-2013
}

Fabián Alfredo Plazas Díaz **

Fecha de recepción: 1 de julio de 2015

Concepto de evaluación: 10 de septiembre de 2015

Fecha de aprobación: 9 de diciembre de 2015

\footnotetext{
Artículo de investigación producto del proyecto: "Análisis de la evolución y la distribución geográfica de la inversión extranjera directa en el sector minero del carbón en Colombia, 2004-2012". La investigación es financiada por el Programa Jóvenes Investigadores e Innovadores 2013 “Virginia Gutiérrez de Pineda” del Departamento Administrativo de Ciencia, Tecnología e Innovación Colciencias y la Universidad Pedagógica y Tecnológica de Colombia UPTC. El proyecto se encuentra adscrito al grupo de investigación Geografía y Ordenamiento Territorial GEOT.

** Docente investigador de la Universidad La Gran Colombia, sede Bogotá. Magister en Estudios Latinoamericanos y Relaciones Internacionales de la Universidad Andina Simón Bolívar, sede Ecuador y Licenciado en Ciencias Sociales de la Universidad Pedagógica y Tecnológica de Colombia UPTC. Tunja, Colombia. Dirección postal: 111711. Correo electrónico: fabian.plazas@ugc.edu.co, fabian.plazas@uptc.edu.co
} 


\section{Resumen}

En este artículo se analiza la evolución de los flujos de inversión extranjera directa (IED) en el sector minas y canteras y en la extracción de carbón, lignito y turba en Colombia en el periodo de 2004 a 2013, utilizando datos estadísticos del Banco de la República y del Sistema de Información Minero Colombiano. Se presenta un panorama del sector minero del carbón en Colombia y la evolución de la IED en el periodo descrito. Se concluye que el sector minero del carbón en Colombia posee un enorme potencial que favoreció la entrada de capitales foráneos durante el periodo, pero terminó siendo un indicador de la primarización de la IED en el país en el mismo periodo.

Palabras clave: desarrollo económico, inversión extranjera directa, geografía económica, minería.

Clasificación JEL: O1, F21, L72.

\section{Abstract}

This article studies the evolution of foreign direct investment (FDI) in the mining and quarrying sector and the extraction of coal, lignite and peat in Colombia in the period 2004-2013 using statistics from the central bank of Colombia (Banco de la República) and from the Colombian Mining Information System. An outlook of the coal mining industry in Colombia and the evolution of IED are presented for the described period. We conclude that coal mining in Colombia has enormous potential that favored the entry of foreign capital during the period, but ended up being an indicator of primarization of IED in the country.

Keywords: economic development, foreign investment, economic geography, mining. 


\section{Resumo}

Este artigo discute a evolução do investimento estrangeiro direto (IED) no setor de mineração e pedreiras e extracção de carvão, lignite e turfa na Colômbia é analisada no período de 2004-2013, utilizando as estatísticas do Banco da República e Sistema de Informação de mineração colombiana. Uma visão geral do setor de mineração de carvão na Colômbia é feito e da evolução do IED ocorre no período descrito. Concluiu- se que o setor de mineração de carvão na Colômbia tem um enorme potencial que favoreceu a entrada de capital estrangeiro durante o período, mas acabou sendo um indicador de primarização de IED no país durante o mesmo período .

Palavras-chave: desenvolvimento Económico, o investimento estrangeiro, geografia econômica, Mineração. 


\section{INTRODUCCIÓN}

Durante la década de 1990, la mayoría de países de América Latina (AL) comenzaron a liberalizar los regímenes de regulación de la inversión extranjera bajo la premisa de estimular el crecimiento económico interno con la entrada de capitales foráneos. Algunas de estas políticas fueron promovidas por Estados Unidos (EU), el Banco Mundial (BM) y el Fondo Monetario Internacional (FMI), en el marco del paquete de políticas neoliberales para la región, las cuales buscaban la aplicación de un conjunto de reformas económicas de apertura comercial y desregulación del mercado financiero, con la finalidad de reducir la protección arancelaria, la flexibilización del mercado de trabajo y crear un mercado libre de capitales (Unctad, 2013). En este contexto, los países de AL redujeron sus aranceles y subsidios, eliminaron las barreras a la inversión extranjera, disminuyeron el gasto público y minimizaron la participación del Estado en la economía. En Colombia, los mayores niveles de internacionalización y apertura económica se dieron también a principios de la década de 1990 y consistieron particularmente en la reducción de barreras al comercio exterior y a la inversión extranjera directa (IED).

En Colombia, la IED es aquella que proviene de una persona natural o jurídica desde el exterior, cuyo capital es invertido con la intención de tener injerencia directa, a largo plazo, en el desarrollo de una firma, a través de la participación en otras empresas ya establecidas o por medio del establecimiento de una filial de la empresa inversora (Ramírez \& Flórez, 2006). Para el Banco de la República de Colombia

la inversión [extranjera] directa es una categoría de la inversión 
internacional asociada con el significativo grado de control que un extranjero (o nacional) adquiere sobre una empresa residente (o fuera del país). El grado de control se define teniendo en cuenta criterios como la activa participación del inversionista extranjero en la gestión de la empresa y el porcentaje de sus acciones en la misma. (Banco de la República, 2014)

De acuerdo con la literatura económica (Solow, 1956; Swan, 1956; Rubini \& Naranjo, 1997), la IED es considerada una variable útil para estimular el crecimiento económico de un país y existen teorías como la neoclásica del crecimiento económico y la teoría del crecimiento endógeno que defienden y desarrollan dicha importancia. Sin embargo, en oposición a los argumentos de los beneficios de la IED, la teoría estructuralista de la Cepal ha llegado a cuestionar los alcances de la inversión foránea estimando que su aporte al crecimiento económico puede llegar a ser mínimo y sus beneficios dependerán del sector económico al que dichas inversiones están dirigidas. Según cifras oficiales del Banco de la República (2014), durante el periodo de apertura y desregulación de la inversión extranjera de 1994 a 2013, en Colombia se han registrado flujos de IED que superan los 118.473 millones de dólares (mUSD) distribuidos en los diferentes sectores económicos y regiones geográficas del país.
En los últimos diez años, la IED ha mostrado en Colombia una tendencia de concentración hacia los recursos naturales, impactando particularmente en los sectores primarios del petróleo y la minería, sobre todo en la extracción de carbón, lignito y turba para este último sector. Lo anterior merece toda la atención si se considera que el país atraviesa un periodo en el que se busca promover a los sectores petrolero y minero como dos locomotoras del crecimiento económico de la nación. De acuerdo con el Plan Nacional de Desarrollo Minero, Colombia País Minero Visión al Año 2019, "En el año 2019, la industria minera colombiana será una de las más importantes de Latinoamérica y habrá ampliado significativamente su participación en la economía nacional" (Upme, 2006). Una de las estrategias para ello ha sido la creación de un marco regulatorio que define e incentiva la inversión extranjera en el sector. En este contexto cabe preguntarse ¿cuál ha sido la evolución de los flujos de inversión extranjera directa que han ingresado en el sector minero en Colombia y en particular en la minería del carbón en los últimos diez años?

Actualmente, en el país existe una importante discusión acerca de los beneficios, los riesgos, las amenazas y los efectos ambientales, sociales, culturales, económicos y políticos de la promoción de la industria minera y petrolera como vías para lograr el crecimiento económico y el desarrollo de la nación 
(Contraloría General de la República, 2013 y 2013i). Para contribuir a la discusión de gran interés nacional, el objetivo del artículo consiste en analizar la evolución de los flujos de IED en el sector minero de Colombia, en particular en la extracción de carbón, lignito y turba en el periodo de 2004 a 2013, tomando elementos de la economía y la geografía económica, para poner en relieve algunas relaciones entre la inversión extranjera y su posible impacto sobre la economía nacional, así como aspectos relacionados con la distribución geográfica de la misma. Con ello se espera demostrar que existe una primarización de la IED en el país, gracias a las políticas que promueven a los sectores mineros y la inversión extranjera como estrategias importantes para el crecimiento económico colombiano. De igual manera, se plantea la necesidad de analizar la distribución geográfica y la caracterización de las modalidades de la inversión foránea en el sector minero, para poner en evidencia empírica los posibles riesgos y beneficios de la inversión.

\section{METODOLOGÍA}

La investigación se desarrolló teniendo en cuenta tres teorías de la economía, para analizar y combinar los diversos factores de la evolución de la inversión extranjera directa en el sector minero del carbón en Colombia. En un primer momento, a partir de la literatura especializada, se desarrolló un marco teórico y un estado de la cuestión acerca de las teorías de las ciencias económicas y geográficas que defienden o rechazan los beneficios de la inversión extranjera, haciendo hincapié en la inversión dirigida a los recursos naturales. Se indagó la teoría neoclásica del crecimiento económico (Solow, 1956; Swan, 1956; Rubini \& Naranjo, 1997); la teoría de crecimiento endógeno (Elías et al., 1998; Borensztein, De Gregorio \& Lee, 1998; De Mello, 1999; Zhang 2001), y la teoría estructuralista latinoamericana de la Cepal (Prebish, 1949; Singer, 1950; Hirschman, 1958; Stoneman, 1975; Bornschier, 1980; O’Hearn, 1990).

Una vez desarrollado el marco teórico, se revisó el marco regulatorio de la inversión extranjera en el país, haciendo énfasis en las disposiciones conferidas al sector minero. Posteriormente se sistematizó y analizó la base de datos con información estadística de los flujos de IED registrados en el Banco de la República de Colombia y el Sistema de Información Minero Energético SIMCO de la Unidad de Planeación Minero Energética UPME del Ministerio de Minas y Energía de Colombia. Una vez analizados los datos, se presentaron los resultados para el periodo de 2004 a 2013.

En primer lugar, se indagaron y se analizaron las reservas probadas, indicadas e inferidas de carbón en Colombia, así como su distribución geográfica, para destacar el potencial que representa el sector carbonífero 
del país. En segundo lugar, se desarrolló un contexto económico del sector minero del carbón determinando la producción nacional de carbón por departamentos productores, así como la producción con destino a las exportaciones y el consumo nacional, a parir de datos estadísticos de la Agencia Nacional de Minería (2014). También, se hizo énfasis sobre tres grupos de países importadores de carbón colombiano. Igualmente, se analizó la contribución del sector minero al país, teniendo en cuenta algunos indicadores económicos, como la evolución del producto interno bruto (PIB) y el PIB minero, calculando la participación de los montos a precios corrientes que tiene el sector minero sobre el PIB total anual nacional, utilizando datos del Banco Mundial (2014), Fedesarrollo (2013) y el DANE (2014i).

Posteriormente, se procedió al análisis de la evolución de los flujos de IED por sectores económicos en el país en el periodo indicado. Se calculó la participación porcentual de los flujos de IED en cada sector económico en el total del periodo analizado y se hizo una comparación de la participación de la IED por sector económico en dos periodos de tiempo de 1994 a 2004 y de 2004 a 2013, para hacer evidente la concentración de la IED en los recursos naturales del carbón y del petróleo en el segundo periodo descrito. De igual manera, se analizó la evolución de los flujos de IED en el sector minas y canteras, donde se discriminó la información en IED en la extracción de carbón, lignito y turba, IED en la extracción de minerales metalíferos y la reinversión de utilidades y otras actividades mineras. A dicha información se le calculó la participación y variación porcentual. Finalmente, se analizó la evolución de la IED en la extracción de carbón, lignito y turba en el periodo de 2004 a 2013 y se calculó su participación porcentual en el total de flujos de IE que ingresan en el sector minas y canteras, así como en el total de flujos de IED que entraron al país en el periodo analizado.

\section{MARCO TEÓRICO}

\section{Inversión extranjera directa y creci- miento económico}

Con el surgimiento de las doctrinas sobre crecimiento económico se ha sostenido que la inversión extranjera directa es un factor que contribuye al crecimiento de la producción a largo plazo, debido a que facilita la transferencia de bienes físicos y conocimientos. Autores como Baracaldo et al. (2001), consideran que la IED puede afectar positivamente la demanda de una economía, en la medida en que logre aumentar el tamaño de las firmas del país anfitrión, lo cual generaría incrementos en la productividad, gracias a la difusión del conocimiento y la tecnología entre las diferentes firmas (crowding in effect). No obstante, 
también se sostiene que la IED afectaría negativamente a la demanda, si compite con la inversión nacional por la producción y por la participación en los mercados financieros (crowding out effect). Desde el punto de vista de la oferta, la IED podría provocar cambios en la productividad de los factores y reflejar rendimientos crecientes en el interior de la función de producción, debido a la utilización de bienes intermedios de mejor calidad y costos menores (Baracaldo et al., 2001).

Dentro de los beneficios que se le atribuyen a la IED, autores como Borensztein et al., (1998); Baracaldo et al., (2001); De Mello (1999); Bernal (2012), Gaviria y Gutiérrez (1993) y Zhang (2001), coinciden en afirmar que la IED conduce a una mayor tasa de crecimiento económico y es considerada el principal vehículo para la transferencia de tecnología y conocimiento (know-how) generando externalidades positivas en las economías receptoras. Los autores sostienen que la IED también puede generar incrementos en los empleos y los salarios, mayor diversidad de bienes y servicios producidos en el país anfitrión, difusión de conocimientos para mejorar la productividad y los esquemas organizativos de los sectores y las empresas, así como aportación de capital en sectores que presentan ventajas comparativas y que cuentan con un potencial hacia el comercio internacional a través de la inversión horizontal o vertical. Según la Organización para la
Cooperación Económica y el Desarrollo (OCDE, 2011), la IED es un elemento clave en la rápida evolución de la integración económica internacional y constituye un medio para establecer vínculos directos, estables y de larga duración entre las economías de diversos países.

Sin embargo, autores como Elías et al. (1998), Carkovic y Levine (2002), Alfaro (2003), Loja y Torres (2013), discuten los mencionados beneficios de la IED afirmando que el aporte al crecimiento económico es mínimo o negativo y depende fundamentalmente del sector económico al que la inversión se dirige. En este sentido, Alfaro (2003) considera que los flujos de IED dirigidos hacia el sector primario, como por ejemplo, la inversión en minas, canteras o petróleo, o ambos, tienden a mostrar un efecto negativo sobre el crecimiento de una economía, debido a que las utilidades de la inversión se obtienen a corto y medio plazo, mientras que a largo plazo en el país anfitrión la inversión genera una importante huella ambiental y una pérdida de recursos naturales que puede sobrepasar los costos y las utilidades inicialmente obtenidas.

Por su parte, Elías et al. (1998) sostienen que la IED puede constituirse en una amenaza a las economías nacionales, teniendo en cuenta el impacto que tiene sobre el medio ambiente, el incremento de empresas transnacionales desplazando a las empresas 
domésticas (crowdingout), la privatización de empresas públicas y la sobreexplotación de los recursos naturales. Al mismo tiempo, Bernal (2012) afirma que la IED puede promover una ideología de consumo masivo dentro de la sociedad, además de advertir los riesgos asociados a la corrupción por parte de las empresas multinacionales para inducir la toma de decisiones por parte del Estado y los gobiernos, priorizando el beneficio particular, sobre los bienes sociales, culturales, económicos y ambientales de una nación.

Desde el punto de vista de la teoría neoclásica del crecimiento económi$c o$, la IED tiene efectos únicamente a corto plazo, debido a que el producto de la economía a largo plazo únicamente puede ser afectado por los avances tecnológicos y el crecimiento de la fuerza de trabajo. La teoría neoclásica se debe a los aportes de Solow (1956) y Swan (1956), quienes intentaron guiar de forma analítica el crecimiento económico de un país a largo plazo, a partir de los factores de acumulación de capital físico, el trabajo y el progreso tecnológico, siendo las fuerzas motoras del crecimiento económico. Con relación a la inversión extranjera, la visión neoclásica señala que es un factor que contribuye al aumento del stock de capital y por ende al crecimiento económico, donde el flujo de capitales extranjeros es un recurso que contribuye a la función de producción, puesto que es un mecanismo de mercado para transferir tecnología y capital desde la economía global hacia regiones menos desarrolladas $(\mathrm{Ru}-$ bini \& Naranjo, 1997).

De acuerdo con la función de producción neoclásica, la IED puede contribuir en el aumento del stock de capital físico, las fuerza de trabajo y el estado de la tecnología, siempre y cuando se consideren algunos de los siguientes supuestos. Dado el estado de la tecnología, es probable que la IED genere una duplicación tanto de la cantidad de capital como de la cantidad de trabajo y por ende de la producción. En este sentido se considera que la presencia de una economía cerrada y la no intervención del Estado, es un estímulo al crecimiento económico, ya que implica que el gasto público es cero y por lo tanto la producción es igual a la renta. Sin embargo, de acuerdo con Loja y Torres (2013), los modelos neoclásicos presentan supuestos demasiados restrictivos, tales como mercados con competencia perfecta, retornos constantes de escala y la productividad marginal decreciente, por lo que se podría concluir que este modelo no explica adecuadamente los efectos de la IED en el crecimiento económico de un país.

Desde el punto de vista de la teoría del crecimiento endógeno, la IED es considerada como una combinación de stock de capital, tecnología y conocimiento. La teoría considera que la IED contribuye al aumentar el stock de experiencia o conocimientos de una 
economía (know-how) y sostiene que los determinantes del crecimiento económico son vistos como fundamentos endógenos (Elías et al., 1998). Desde este punto de vista, la IED es un vínculo importante para la transferencia de tecnología y contribuye relativamente al crecimiento de la inversión nacional. Sin embargo, también se aclara que la IED aporta al crecimiento económico solo cuando existe una capacidad de absorción suficiente de las tecnologías avanzadas en la economía del país receptor, para lo cual el país anfitrión debe contar con un umbral mínimo de capital humano (Borensztein, De Gregorio \& Lee, 1998).

De acuerdo con la teoría endógena, un aumento en el número de variables de capital requiere la adaptación de la tecnología disponible en los países más avanzados, para permitir la introducción de un nuevo tipo de bienes de capital. Según esta teoría, la IED es el canal principal del progreso tecnológico, suponiendo la existencia de un efecto "catch-up" y considerando que es más barato imitar los productos que ya existen que crear nuevos productos, bajo el supuesto de que el costo de instalación depende positivamente del número de variedades de capital que son producidos en el país en comparación con los que se producen en los países más avanzados (Borja, 1958). Adicionalmente, Borensztein, De Gregorio y Lee (1998), De Mello (1999), Zhang (2001), sugieren que la IED contribuye sustancialmente al crecimiento económico, siempre y cuando el país receptor aproveche las externalidades que le brinda la entrada de flujos de IED. Finalmente, desde la teoría del crecimiento endógeno, autores como Romer (1986 y 1990), Sala-I-Martin (1994), Mankiw, Romery Wheil (1992), han incluido nuevos factores y conceptos para analizar la relación entre la inversión extranjera y el crecimiento económico tales como: la endogeneidad del progreso técnico, la importancia de la acumulación de capital humano, la relevancia de la inversión en investigación y desarrollo (I \& D), la competencia imperfecta, las externalidades producto de la difusión del conocimiento, la importancia de las instituciones y el manejo de la política económica.

Ahora bien, desde el punto de vista de la teoría estructuralista latinoamericana, la cual surge con la Comisión Económica para América Latina y el Caribe CEPAL, con autores como Prebish (1949), Singer (1950) y Hirschman (1958), la IED genera efectos negativos en el crecimiento económico, dada la relación de dependencia bajo el enfoque centro- periferia. Desde este enfoque crítico de la CEPAL, la inversión extranjera puede influir positivamente en el crecimiento económico a corto plazo, mientras a largo plazo produce el efecto contrario. A corto plazo, el incremento de la inversión redundará en un aumento de la producción y del consumo, lo que provoca una elevación de la tasa de 
crecimiento económico del país. Sin embargo, a medida que pasa el tiempo y los proyectos se llevan a cabo, se pueden evidenciar los efectos adversos de la inversión extranjera, gracias a la "descapitalización" y a la "desarticulación" de los proyectos, una vez obtenidos los beneficios (Stoneman, 1975; Bornschier, 1980; O’Hearn, 1990).

Según el pensamiento de la CEPAL, el comercio exterior y en especial la IED podrían causar el subdesarrollo, porque las ganancias repatriadas por compañías extranjeras hacia las metrópolis exceden el valor de su inversión original, deteriorando de esta manera los términos de intercambio. Adicionalmente, se sostiene que la IED no genera demanda de bienes de producción interna y no da lugar al surgimiento de nuevas industrias nacionales, dado que no incrementa los salarios de los trabajadores de las empresas de procedencia extranjera y por tanto no tiene efectos profundos en el mercado interno. De igual manera, la IED no produce transferencia de tecnología de punta y no influye en el crecimiento de nuevos tipos de industrias que utilicen nuevos procesos tecnológicos (Haber, 1997, p. 164).

En este contexto, Borja (1958) agrupa los efectos negativos de la inversión extranjera en cinco categorías: a) el desplazamiento de productores locales por causa de la IED, b) los flujos de comercio y de capital generados por la IED son asumidos como negativos a largo plazo para la economía receptora, debido a que las empresas extranjeras tienden a importar más de lo que exportan y a enviar al exterior más capital del que traen como inversión original, c) la tecnología que las empresas introducen son obsoletas para los países en desarrollo, no realizan actividades de investigación en la economía local y sus tecnologías no son apropiadas a las necesidades sociales de los países receptores, d) en cuanto a los efectos distributivos, el argumento es que debido a los salarios más altos pagados por las empresas extranjeras, así como a los modelos de consumo que ellas promueven, tienen un efecto negativo en los patrones regresivos de distribución del ingreso en los países subdesarrollados, e) las empresas extranjeras desarrollan alianzas con las burguesías locales, lo cual resulta en una agravación de la tendencia histórica de exclusión política y marginación económica de la mayoría de la población.

En síntesis, de acuerdo con las teorías expuestas, la inversión extranjera tiene un efecto medible a través del aumento del stock de capital y de los beneficios que se derivan de la transferencia de conocimiento y tecnología para mejorar e innovar en los sistemas de producción y de esta manera contribuir al crecimiento económico. Para la teoría neoclásica, los efectos de la IED se dan a corto plazo y los beneficios se pueden medir por la cantidad de capital invertido, la generación de empleo 
Análisis de la evolución de la inversión extranjera directa en el sector minero del carbón en Colombia de 2004 a 2013

Fabián Alfredo Plazas Díaz

y la transferencia de tecnología. Para la teoría endógena, los beneficios pueden darse según la cualificación del factor humano y por las estrategias que utilice el país anfitrión para absorber y saber aprovechar las transferencias de capital, conocimiento y tecnología que provienen del exterior y que pueden ser usadas en el desarrollo de las cadenas productivas de los sectores de la economía local. Por su parte, el estructuralismo latinoamericano aporta una crítica a los efectos de la inversión extranjera y considera que no presenta mayores beneficios para el país receptor, debido principalmente a los factores de dependencia que terminan por deteriorar los términos de intercambio, además de los impactos negativos producto de la descapitalización y la desarticulación de los proyectos. Para la investigación, se considera la teoría del crecimiento endógeno y la de la Cepal, como dos teorías explicativas adecuadas para analizar la evolución de la IED en la minería del carbón en Colombia.

\section{RESULTADOS}

Los resultados dan cuenta de la evolución de la IED en el sector minas y canteras y en la extracción de carbón, lignito y turba en Colombia en el periodo de 2004 a 2013. Se presenta un panorama del sector minero del carbón en Colombia, tomando en cuenta aspectos como las reservas, la producción y las exportaciones de carbón, y se indica la evolución de la IED en el periodo descrito.

\section{Generalidades de la regulación de la inversión extranjera directa en Colombia}

En Colombia el régimen legal de la inversión extranjera se transformó como resultado de la transición de una economía condicionada al capital extranjero a una economía abierta con una política activa de atracción de la inversión extranjera, donde se pueden distinguir tres etapas (Fedesarrollo, 2007). En la primera, desde finales de 1960 a comienzos de 1990 , la regulación de la inversión extranjera fue restringida, debido al modelo de industrialización por sustitución de importaciones (ISI), que promovía el desarrollo productivo doméstico a partir de recursos internos. En esta primera etapa, la legislación restringía a todos los sectores que podían recibir flujos de inversión extranjera y la libre transferencia de capital y utilidades en línea con el régimen de control de cambios que operaba en el país (Fedesarrollo, 2007).

La segunda etapa comienza con la apertura económica y las reformas neoliberales de la década de los noventa, cuando el régimen de inversión extranjera se modificó con la Ley 9 de 1991, que promocionó la internacionalización y la modernización de la economía colombiana. Dicha ley le otorgó el mismo trato nacional a los inversionistas extranjeros y a partir de los principios de igualdad, universalidad y automaticidad se eliminaron las 
restricciones a la inversión extranjera en la mayoría de los sectores y se autorizó la libre transferencia de capital y utilidades, salvo en los sectores de telecomunicaciones, transporte aéreo y marítimo, y continuó totalmente prohibida en lo relacionado con las basuras toxicas, peligrosas o radioactivas, en el sector inmobiliario y en defensa nacional (Resolución 9 de 1991).

La tercera etapa inicia con lo estipulado en el Decreto 2080 de 2000 y continúa en la actualidad, se caracteriza por la profundización de las reformas al régimen de IED adoptado a comienzos de los noventa y a partir de los mecanismos de simplicidad, autorización automática, igualdad de trato y estabilidad al inversionista se ha buscado mejorar y promover la atracción de capitales extranjeros al país. Actualmente, la legislación autoriza la inversión de capital extranjero en todos los sectores de la economía, excepto en actividades de defensa y seguridad nacional y en el procesamiento, disposición y desecho de basuras tóxicas, peligrosas o radioactivas no producidas en el país. En el Decreto 2080 también es posible distinguir dos modalidades de inversión extranjera: la inversión extranjera directa (IED) y la inversión en portafolio ${ }^{1}$.
En Colombia, los flujos de IED se han convertido en la principal fuente de financiación del déficit corriente de la balanza de pagos y son registrados ante el Banco de la República de Colombia, que publica informes estadísticos de los flujos de IED que ingresan al país y emite informes dirigidos al Ministerio de Minas y Energía y a la Unidad de Planeación Minero Energética UPME de este Ministerio, en los temas relacionados con la minería y la actividad petrolera. Las principales normas que rigen el registro de la IED son el Estatuto Cambiario Colombiano (Ley 9 de 1991) y el Régimen General de Inversión Extranjera en Colombia, consignado en el Decreto 2080 de 2000. El Decreto 2080 contiene seis definiciones en las que una persona natural o jurídica puede participar de un proceso de transferencia de capital en el país (art.3 Decreto 2080), así como las modalidades de inversión donde se destacan los bienes tangibles e intangibles y las diferentes modalidades de aportes que un no nacional puede realizar en el país (art. 5 Decreto 2080).

Con relación a la inversión extranjera en los sectores minería y petróleo, la Ley 9 de 1991 en su artículo 15, "Régimen de Inversiones", estipula que mediante normas de carácter general

\footnotetext{
Es importante aclarar que para desarrollar el objetivo que se propone en el artículo de investigación, la inversión de portafolio no será parte del objeto de estudio, debido a que esta responde a diferentes motivaciones e implicaciones que se escapan del análisis central de la investigación.
} 
se podrán establecer regímenes excepcionales entre el inversionista y estos sectores. En este sentido, en el Decreto 2080 de 2000 (Titulo III Capítulo II), se estipula que las inversiones de capitales del exterior para la exploración y explotación de petróleo y gas natural, para proyectos de refinación, transporte y distribución de hidrocarburos $\mathrm{y}$ para la exploración, explotación, beneficio y transformación de minerales, estarán sujetas al cumplimiento de las normas que regulan dichas actividades. En estos casos, el régimen cambiario de los sectores de hidrocarburos y minería, incluidas las actividades de exploración y explotación de petróleo, gas natural, carbón, ferroníquel o uranio, estará sujeto a las regulaciones de la Junta Directiva del Banco de la República, conforme a sus competencias. Adicionalmente, las empresas que cuenten en su capital con inversión extranjera y que realicen actividades de exploración y explotación de petróleo, gas natural o carbón, o que se dediquen exclusivamente a la prestación de servicios técnicos para la exploración o explotación de dichos recursos, no están obligadas a reintegrar al país sus divisas (art. 16 de la Ley 9 de 1991; art. 23 del Decreto 2080 de 2000; Decreto 1844 de 2003).

De igual manera, en la Ley 658 de 2001, Código de Minas, se define lo pertinente a la actividad minera, en cuanto a los derechos de exploración y explotación, las zonas reservadas, excluidas y restringidas, lo correspondiente a la prospección y los contratos de concesión, entre otros, en donde a partir del criterio de igualdad de trato, el inversionista extranjero está en la posibilidad de invertir sin discriminación alguna. Finalmente, mediante la Ley 963 del 8 de julio de 2005 se establecieron los contratos de estabilidad jurídica, reglamentados por el Decreto 2950 de 2005 y el Decreto 1474 de 2008, los cuales se convirtieron en incentivos para proteger a los inversionistas de los cambios desfavorables en las leyes o reglamentos detallados en los contratos entre el Gobierno y las empresas (tanto extranjeras como nacionales) y de esta manera garantizar a los inversionistas de más de US\$1.490.000 millones que si cambian las normas o interpretaciones que están específicamente identificadas en los contratos como determinantes de la inversión, la inversión no se verá afectada.

\section{Breve contexto del sector minero del carbón en Colombia de 2004 a 2013}

Colombia se caracteriza por poseer las mayores reservas de carbón de América Latina y es uno de los diez primeros productores del recurso en el mundo, lo cual convierte a dicho sector en atractivo para la inversión extranjera. El país cuenta con un potencial de 16.436 millones de toneladas (Mt) de carbón, de las cuales $6.419 \mathrm{Mt}$ son medidas y distribuidas en la cordillera occidental, central y oriental del país. Dentro de este potencial 4.571 Mt son indicadas, 4.237 Mt son inferidas y 1.209 
Mt son recursos hipotéticos (Ministerio de Minas y Energía, 2012). El país cuenta con carbones de tipo antracito y bituminoso caracterizados por su alto contenido de carbono y poder calorífico, los cuales pueden ser utilizados en la industria térmica y siderúrgica y en la generación de energía. También existen carbones tipo subbituminoso y lignito que contienen un menor grado de poder calorífico y mayores niveles de material volátil, humedad y ceniza, pero también pueden ser usados en la generación de energía eléctrica, generación de vapor y en algunos procesos industriales (Upme, 2005, 2012).

La región de Colombia que concentra las reservas, la producción y la exportación de carbón es la atlántica en los departamentos de La Guajira, Cesar y Córdoba y en el interior del país en los departamentos de Antioquia, Valle del Cauca, Cauca, Boyacá, Cundinamarca, Santander y Norte de
Santander (Figura 1). La zona de la Guajira lidera las reservas de carbón con el $57 \%$ del total nacional, distribuida en las áreas de Cerrejón Norte, Cerrejón Central y Cerrejón Sur. La región atlántica con los departamentos de La Guajira, Cesar y Córdoba registra el $89 \%$ del total de las reservas del país y es una región favorable a las exportaciones por encontrarse en zona costera. El otro $10 \%$ de las reservas se encuentra en los departamentos de Antioquia, Valle del Cauca, Cundinamarca, Boyacá, Santander y Norte de Santander (UPME, 2012).

En Colombia, en el periodo de 2004 a 2013, la producción nacional de carbón mantuvo un crecimiento promedio anual del $2.4 \%$. La producción nacional durante el periodo fue de 735.129.279 toneladas ( $t$ ), en donde los departamentos del Cesar y la Guajira concentraron cerca el $90 \%$ del total

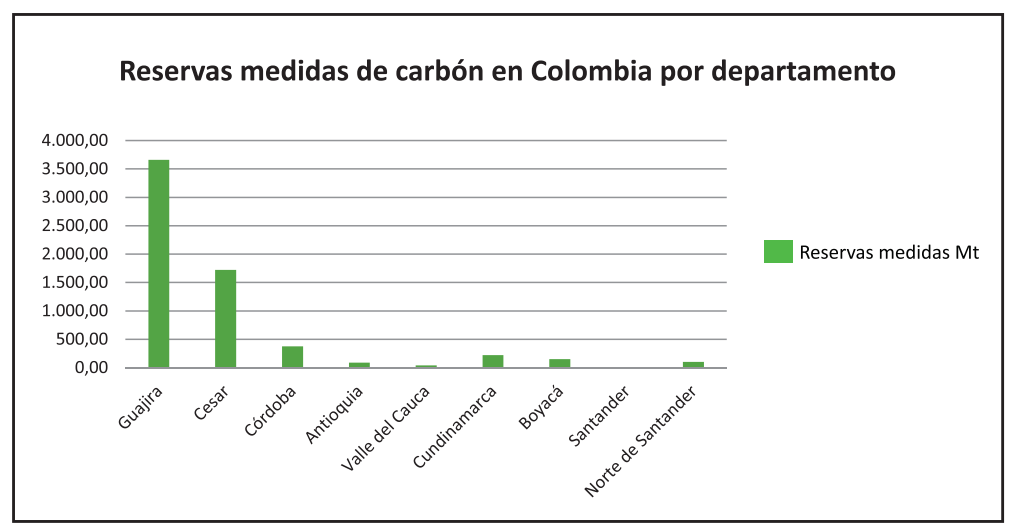

Figura 1. Reservas medidas de carbón en Colombia por departamento Fuente: elaboración propia con base en los datos de la Agencia Nacional de Minería, 2014. 

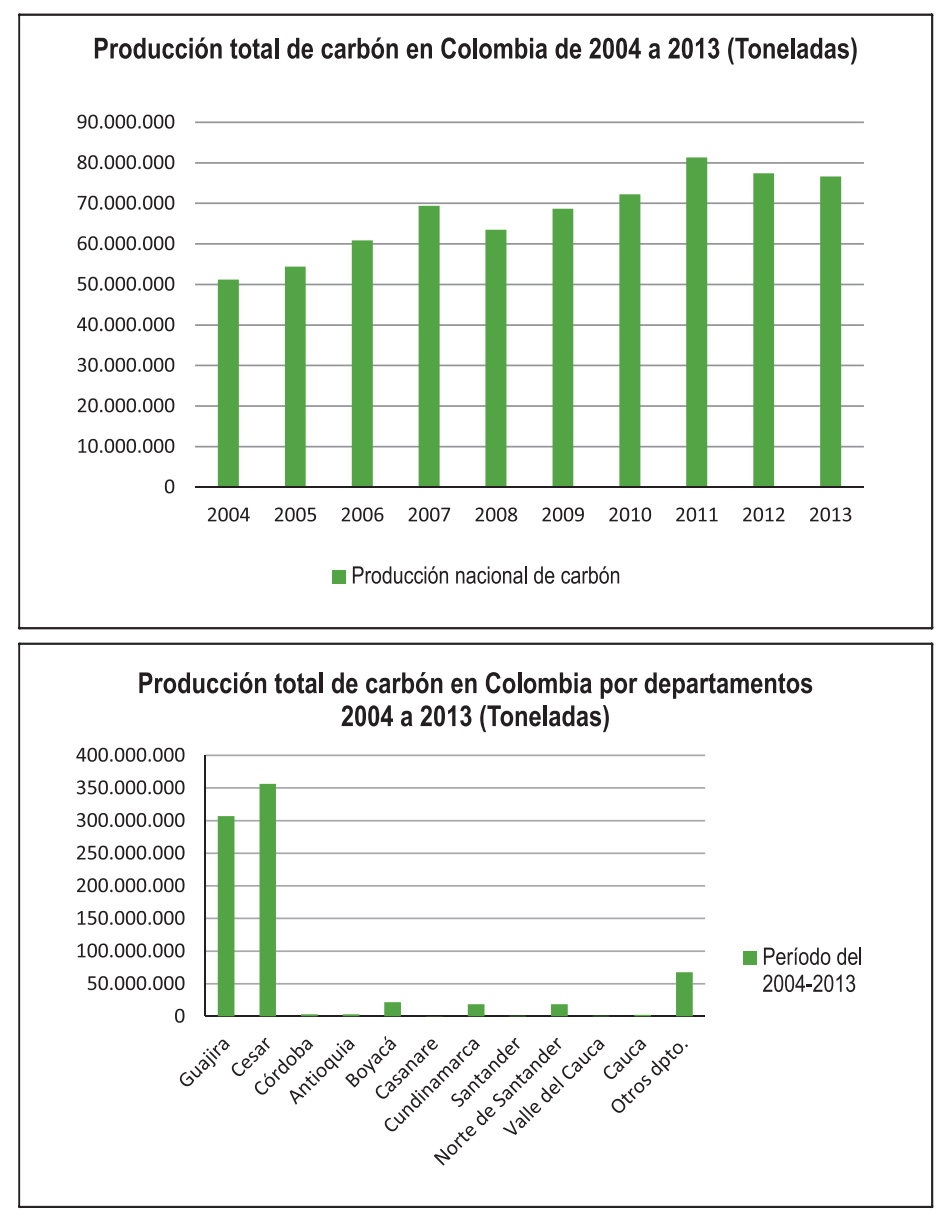

Figura 2. Producción total de carbón en Colombia y por departamentos de 2004 a 2013 Fuente: elaboración propia con base en los datos de la Unidad de Planeación Minero Energética (Upme, 2010).

de la producción, seguidos por Norte de Santander (3\%), Boyacá (2\%), Cundinamarca (2\%), Córdoba (1\%), Antioquia (1\%) y Santander (1\%) (Figura 2) (Agencia Nacional de Minería, 2014). Adicionalmente, el $91 \%$ de la producción nacional de carbón en el periodo analizado fue destinada a la exportación (Upme, 2010). Con relación a los departamentos del Cesar y la Guaji$\mathrm{ra}$, vale resaltar que gracias a su cercanía con el mar se facilitan las exportaciones, a la vez que se concentran las mayores reservas probadas y probables de carbón en el país.

De acuerdo con la información suministrada por la Agencia Nacional de 
Minería (2014), la producción de carbón en Colombia durante el periodo de análisis muestra tres momentos particulares. El primero, de 2004 a 2008, donde la producción de carbón mantiene un crecimiento sostenido con una variación del $10.74 \%$ en 2005 , equivalente a una producción de 59.675.099 t. En 2006 la variación fue de $11 \%$ con 66.191.863 t. En 2007 la variación fue del $5.61 \%$. Para 2008 la producción fue de $73.502 .070 \mathrm{t}$, con una variación del $5 \%$ anual. En el segundo momento se presentó una disminución de la producción de carbón en el país que coincide con la crisis económica mundial, con una variación de $-1 \%$ en 2009 , equivalente a 72.807 .413 t. En 2010 la variación de la producción de carbón fue de $2 \%$, equivalente a $74.350 .133 \mathrm{t}$. El tercer momento se caracteriza por un repunte en la producción de carbón en 2011 y 2012, con una variación de $15.40 \%$ y $4 \%$, respectivamente. Finalmente, en 2013, la producción disminuye levemente con una variación de $-4 \%$, equivalente a 85.496.062 t. El total de la producción de carbón durante el periodo fue de $735.129 .279 \mathrm{t}$.

Por otra parte, las exportaciones de carbón en Colombia en el periodo analizado sumaron los 50.224 millones de dólares FOB consolidándose como el segundo producto mayor exportado del país después del petróleo (Banco de la República, 2014i). De 2004 a 2010 se da un crecimiento sostenido de las exportaciones el cual muestra su repunte en 2011 con 8.397 millones de dólares
FOB. En los dos años siguientes se presenta una disminución en las exportaciones con una variación de $-7 \%$ y $-14 \%$, respectivamente. La participación promedio del carbón en el total de las exportaciones nacionales durante el periodo fue del $13 \%$, siendo 2009 el año de mayor participación con el $16 \%$ del total. Con relación a las toneladas de carbón exportadas, en el periodo se alcanzó la suma de 675.626 .567 toneladas que representan el $91 \%$ del total de la producción de carbón nacional (Figura 3) (Agencia Nacional de Minería, 2014; Dane, 2014).

Las exportaciones del carbón colombiano en el periodo de 2004 a 2013 tienen como principales destinos los mercados de Estados Unidos, Países Bajos, Reino Unido, Turquía, Israel, Chile, Brasil, Portugal, España, Francia, Italia, Dinamarca, Canadá, Puerto Rico, Irlanda y China, que conforman un primer grupo de países importadores que superan los diez millones de toneladas en el periodo analizado. Un segundo grupo lo componen Islas Caimán, Perú, República Dominicana, Alemania, México, Guatemala, República de Corea, Croacia, Escocia, Bélgica, Argentina, Taiwán, Marruecos, Panamá, Eslovenia, India, Islas anglonormandas, Guadalupe y Suiza, cuya importación se encuentra entre los diez y un millón de toneladas de carbón durante el periodo. Finalmente, un tercer grupo lo componen los países cuyas importaciones están entre un millón y cien mil toneladas de carbón: Finlandia, 

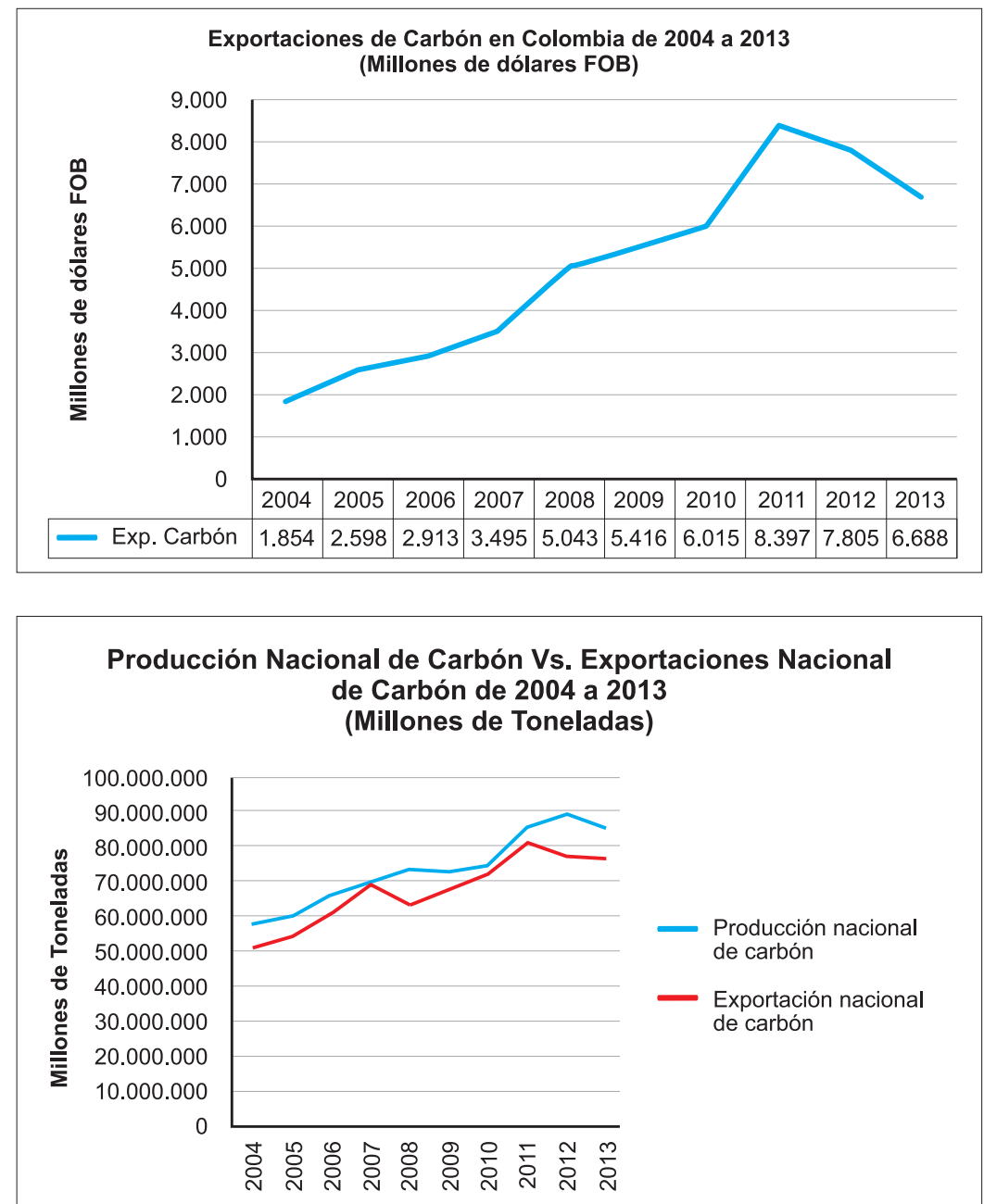

Figura 3. Exportaciones y producción de carbón en Colombia de 2004 a 2013

Fuente: elaboración propia con base en datos de Banco de la Republica (2014i) y Dane (2014).

Polonia, Grecia, Egipto, Ucrania, Cuba y Suecia. El resto de países que siguen presentan importaciones de menos de cien mil toneladas: Malasia, Noruega, Trinidad y Tobago, Vietnam, República Checa, Arabia Saudita, Curazao, Singapur, El Salvador, Irán y Rusia (Dane, 2014) (Figura 4).
Ahora bien, antes de presentar los resultados de la evolución de los flujos de IED en Colombia destinados al sector minas y canteras y a la extracción de carbón, lignito y turba, es importante mencionar que la participación porcentual de la minería en el total del PIB nacional en el periodo de 2000 a 

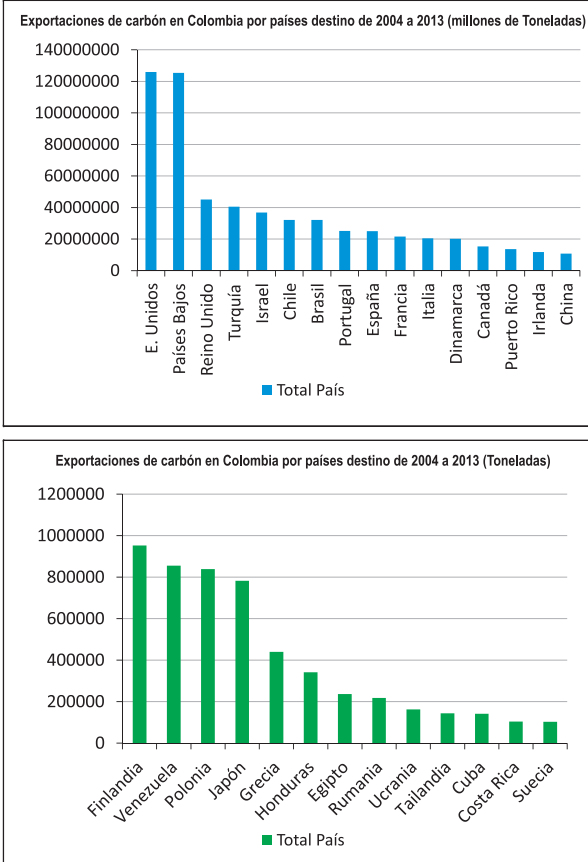

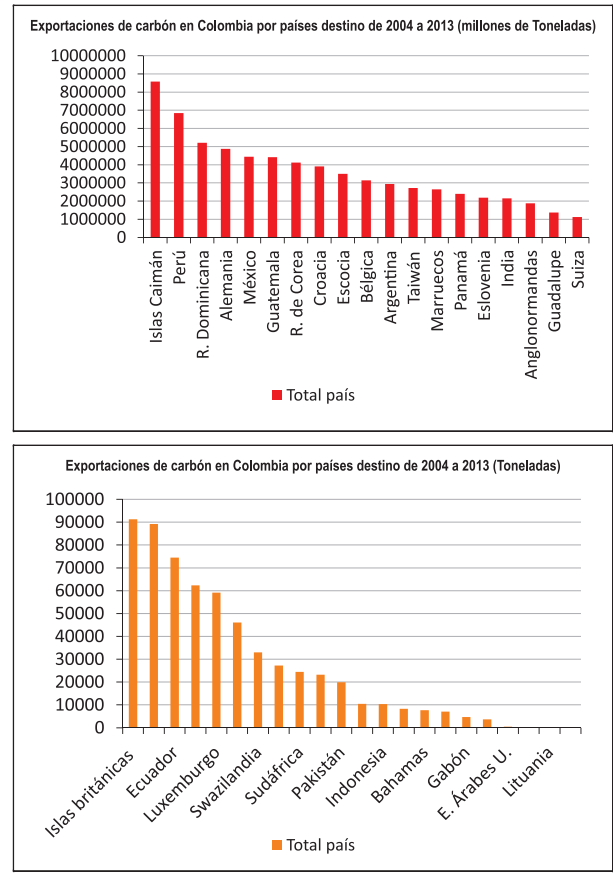

Figura 4. Exportaciones de carbón en Colombia por grupos de países destino de 2004 a 2013 Fuente: elaboración propia a partir del Banco de Datos del Dane (2014).

2012 presentó la siguiente dinámica. De acuerdo con Fedesarrollo (2013), en el año 2000 la minería participo con el $1,80 \%$ del total del PIB, la cual presentó un aumento en su participación en el año 2003 con el 2,30 \% del total. Para el año 2006 se presenta un leve incremento de su participación en el total del PIB con el 2,40\%, el cual desciende y se mantiene estable con el $2,30 \%$ en los años 2009 y 2012 respectivamente. En este sentido, de acuerdo con Rudas (2013), el sector minero presentó unas tasas de crecimiento casi siempre positivas y superiores o cercanas al crecimiento del PIB en su conjunto.
Evolución de los flujos de inversión extranjera directa en Colombia por sector económico y en el sector minas y canteras en el periodo de 2004 a 2013

En Colombia, el total de flujos de IED registrados en el Banco de la República en el periodo de 2004 a 2013 alcanzan la suma total de 99.439 millones de dólares (mUSD) de los cuales, 20.847 millones se han invertido en el sector minas y canteras, que absorbió el $21 \%$ del total de flujos de inversión foránea que ingresaron al país en el periodo citado (Banco de la República, 2014). Desagregando las cifras 
del sector minas y canteras, cerca de 18.649 mUSD (89 \%) fueron invertidos en la extracción de carbón, lignito y turba mientras que $1.967 \mathrm{mUSD}$ (9\%) fueron destinados a la extracción de minerales metalíferos como el cobre, el mineral de hierro y níquel contenido en ferroníquel. Respecto a la reinversión de utilidades de la IED y otras actividades en minería se presentaron saldos negativos particularmente en el año 2007 y 2008, donde se registra una cifra de -794 mUSD y -498 mUSD, respectivamente. Para los años 2005, 2012 y 2013 la reinversión de utilidades fue de $343 \mathrm{mUSD}$, 259 mUSD y 335 mUSD, respectivamente. (Ver Tabla 1 y Figura 5)

Tabla 1. Flujos de IED en Colombia según actividad económica de 2004 a 2013. (Millones de dólares)

\begin{tabular}{|c|c|c|c|c|c|c|c|c|}
\hline Año & $\begin{array}{c}\text { Minas y } \\
\text { canteras } \\
\text { (incluye car- } \\
\text { bón) }\end{array}$ & $\begin{array}{c}\text { Sector } \\
\text { Petróleo }\end{array}$ & $\begin{array}{c}\text { Manufac- } \\
\text { turas }\end{array}$ & $\begin{array}{c}\text { Transportes, al- } \\
\text { macenamientos y } \\
\text { comunicaciones }\end{array}$ & $\begin{array}{c}\text { Servicios fi- } \\
\text { nancieros } \\
\text { yempresa- } \\
\text { riales }\end{array}$ & $\begin{array}{c}\text { Electrici- } \\
\text { dad, gas } \\
\text { y agua }\end{array}$ & $\begin{array}{c}\text { Otras ac- } \\
\text { tividades } \\
\text { económi- } \\
\text { cas** }\end{array}$ & Stock \\
\hline 2004 & 1.246 & 495 & 288 & 481 & 244 & 88 & 279 & 3.122 \\
\hline 2005 & 2.151 & 1.125 & 5.502 & 1.025 & 245 & -252 & 434 & 10.230 \\
\hline 2006 & 1.796 & 1.995 & 815 & 1.065 & 478 & -68 & 663 & 6.744 \\
\hline 2007 & 1.081 & 3.333 & 1.760 & 401 & 1.359 & -129 & 1.042 & 8.847 \\
\hline 2008 & 1.790 & 3.349 & 1.696 & 978 & 1.083 & 156 & 1.476 & 10.528 \\
\hline 2009 & 3.014 & 2.637 & 1.364 & 340 & 711 & -992 & 940 & 8.014 \\
\hline 2010 & 1.838 & 3.080 & 210 & -356 & 916 & 43 & 641 & 6.372 \\
\hline 2011 & 2.480 & 4.700 & 1.214 & 1.760 & 1.160 & 381 & 2.797 & 14.492 \\
\hline 2012 & 2.474 & 5.471 & 1.985 & 1.245 & 1.077 & 672 & 2.103 & 15.027 \\
\hline 2013 & 2.977 & 4.909 & 2.586 & 1.474 & 1.606 & 395 & 2.116 & 16.063 \\
\hline Total & 20.847 & 31.094 & 17.420 & 8.413 & 8.879 & 294 & 12.491 & 99.439 \\
\hline
\end{tabular}

* Otros sectores incluyen: agricultura, caza, silvicultura y pesca, construcción, comercio, restaurantes y hoteles y servicios comunales.

Fuente: elaboración propia con datos oficiales del Banco de la República de Colombia (2014).

En Colombia, en el periodo de 2004 a 2013 , el sector minas y canteras $(20 \%)$ y el sector petróleo (32\%) absorbieron el $52 \%$ del total de flujos de IED que ingresaron al país, lo cual representa \$US 51.941 millones. Así mismo, el sector manufacturas absorbió el $17 \%$ del total, seguido de servicios financieros y empresariales $(9 \%)$, transportes (8\%), otras actividades económicas
$(12 \%)$ y electricidad, gas y agua con tan solo el $0.2 \%$ (ver Figura 6). Al respecto, Garay (2004) sostiene que tradicionalmente la IED en Colombia se ha caracterizado por la dinámica que presenta la explotación de recursos naturales no renovables como el carbón y, en especial, el petróleo. Sin embargo, si comparamos la distribución sectorial de la IED en Colombia por sector 


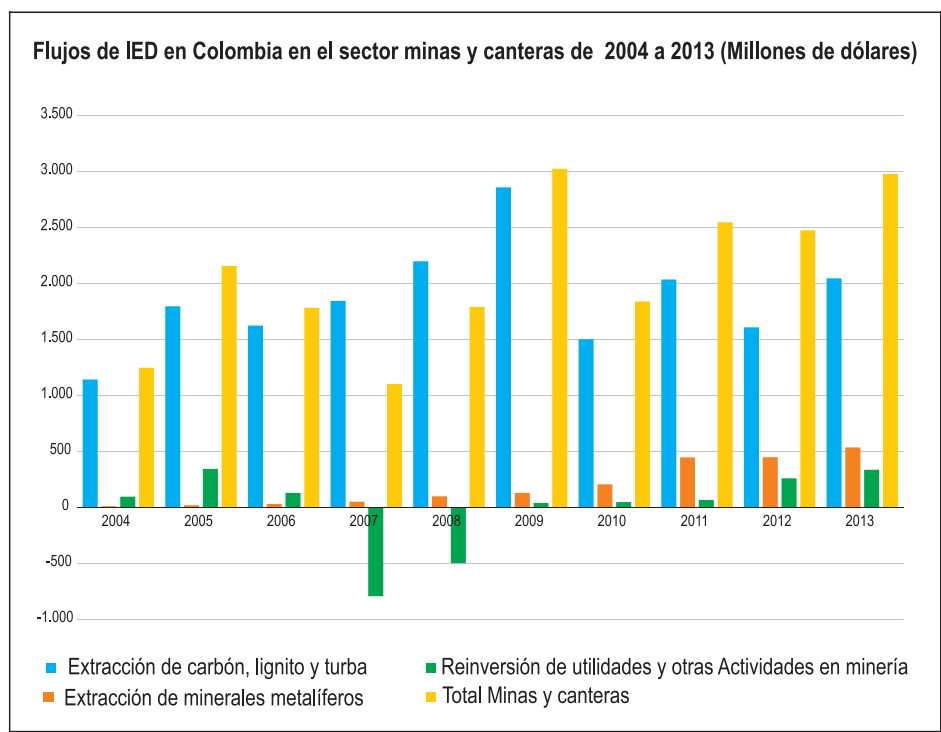

Figura 5. Flujos de IED en Colombia en el sector minas y canteras de 2004 a 2013 Fuente: elaboración propia con datos oficiales del Banco de la República de Colombia (2014).

económico en el periodo de 1994 a 2003, encontramos que los sectores de mayor atracción a la inversión foránea fueron en su orden: servicios financieros y empresariales (23 \%); manufacturas (18\%); electricidad, gas y agua (18\%); minas y canteras $(13 \%)$, transportes, almacenamientos y comunicaciones $(10 \%)$; y finalmente el sector petróleo (7\%). (Figura 6).

Como podemos observar, en el periodo de 2004 a 2013 el sector petróleo ha sido el más beneficiado, pasando de una participación del 8 al $32 \%$ de los flujos de IED respecto al periodo anterior, mientras que el sector minas y canteras pasó de una participación del $17 \%$ al $21 \%$, respectivamente. Por otra parte, el sector manufacturas mantuvo una participación constante en los dos periodos con el $17 \%$, mientras que los sectores afectados por la disminución de IED de un periodo a otro son servicios financieros, pasando de 21 a $9 \%$; transportes, almacenamientos y comunicaciones que pasa del 10 al $8 \%$; y electricidad y gas pasando del $16 \%$ de 1994 a 2004, al $0.2 \%$ en el periodo de 2004 a 2013.

Además, si se observa la participación porcentual del sector minas y canteras en el total de flujos de IED en Colombia en el periodo de 2004 a 2013, se encuentra que para el año 2004 el sector logró atraer el $38 \%$ del total de flujos que ingresaron al país. Para el 2005 la participación fue del $21 \%$ y $26 \%$ para el 2006. En el año 2007 se 


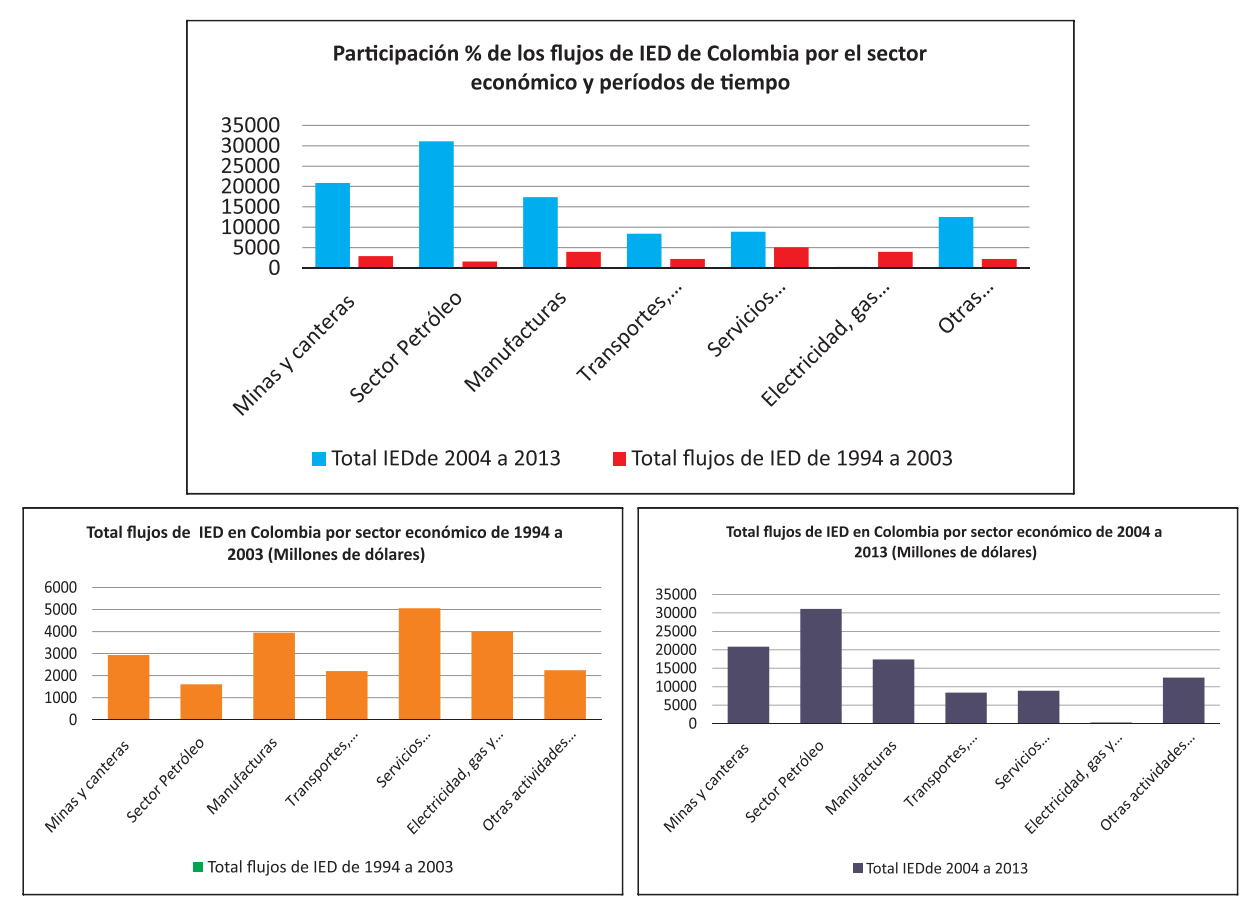

Figura 6. Flujos de IED en Colombia por sector económico y periodos de tiempo Fuente: elaboración propia con base en datos del Banco de la República (2014).

presenta una disminución de flujos de IED hacia el sector que participa del $13 \%$. Para el año 2008 la participación del sector aumenta al $17 \%$ y llega a un repunte en el 2009 del $37 \%$. Para los siguientes años el sector presenta de nuevo una disminución de IED del $29 \%$ en el $2010,17 \%$ en el 2011, $16 \%$ en el 2012 y $18 \%$ en el 2013. En cuanto a los sectores petrolero y minero, los resultados evidencian un importante incremento en los flujos de IED en los últimos años, el cual está relacionado con los altos precios internacionales del carbón, el estable desempeño económico que brindan los sectores, así como por el acompañamiento de las políticas económicas orientadas a promocionarlos como dos locomotoras del crecimiento económico, lo cual las convierte en atractivas para la inversión foránea.

\section{Evolución de los flujos de inversión extranjera directa en la extracción de carbón, lignito y turba en Colombia de 2004 a 2013}

Con relación a la IED en la extracción de carbón, lignito y turba en Colombia, en el periodo de 2004 a 2013, se invirtieron cerca de \$US 18.649 millones, lo cual representó el $18 \%$ del total de IED Nacional. El promedio 
anual de IED para esta actividad fue de \$US 1.865 millones, el cual tuvo un crecimiento sostenido desde 2006 teniendo su mayor repunte en el año 2009 con \$US 2.858 millones. Para el año 2010 se presenta una fuerte caída de IED en esta actividad con una variación de $-47 \%$. En 2011 se presenta una variación de $35 \%$ con \$US 2.035 millones. Para 2012 la variación es de -20 $\%$ con \$US 1.608 millones mientras que en 2013, la variación es de $27 \%$ llegando a un monto \$US 2.045 millones. (Figura 7).

La Figura 8 ilustra la comparación de la variación de los flujos de IED en el sector minas y canteras y en la extracción de carbón, lignito y turba, donde se aprecia que el carbón es el principal captador de IED en el sector minero colombiano.

La Figura 9 ilustra los tres grupos de países inversores en Colombia. Desafortunadamente no fue posible acceder a información que permitiera discriminar los datos de la inversión por país de origen y sector económico destino, dada su inaccesibilidad pública. Por lo tanto la información se presenta de acuerdo con los flujos totales de IED que depositaron los países en el periodo de 2005 a 2013 sin discriminación alguna. En el primer grupo se encuentran los países cuya IED está

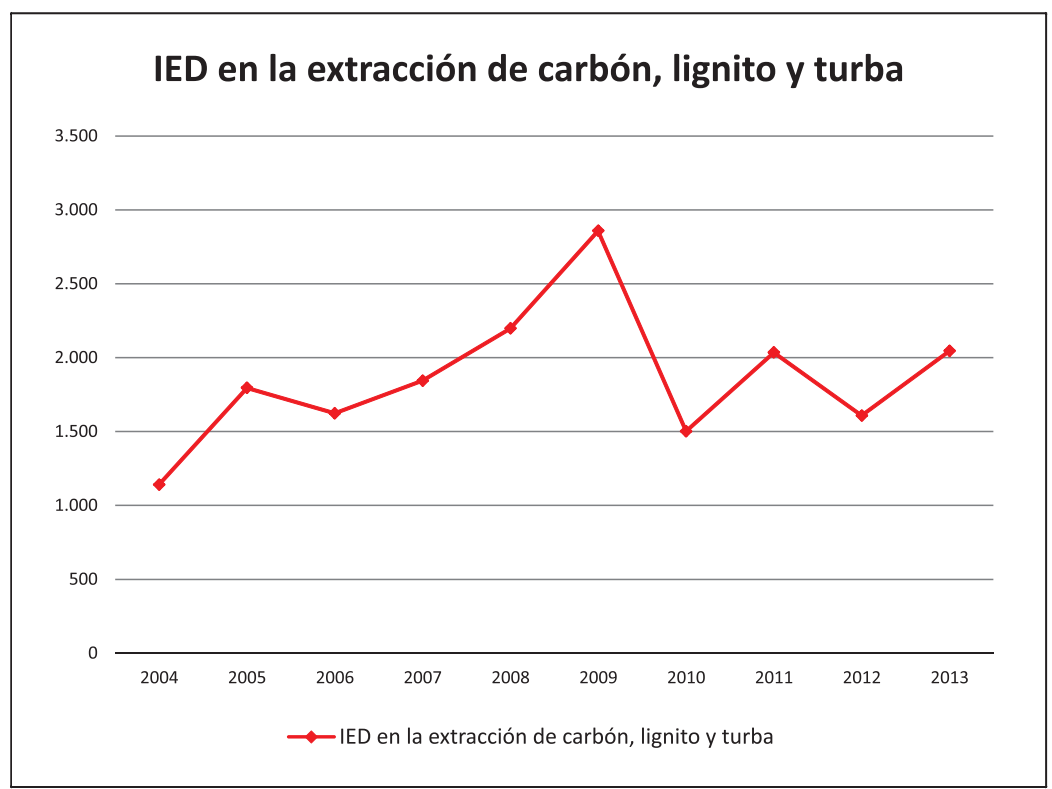

Figura 7. Evolución de los flujos de IED en la extracción de carbón, lignito y turba de 2004 a 2013

Fuente: elaboración propia con datos oficiales del Banco de la República de Colombia (2014) y del Sistema de Información Minero Colombiano SIMCO (2014). 


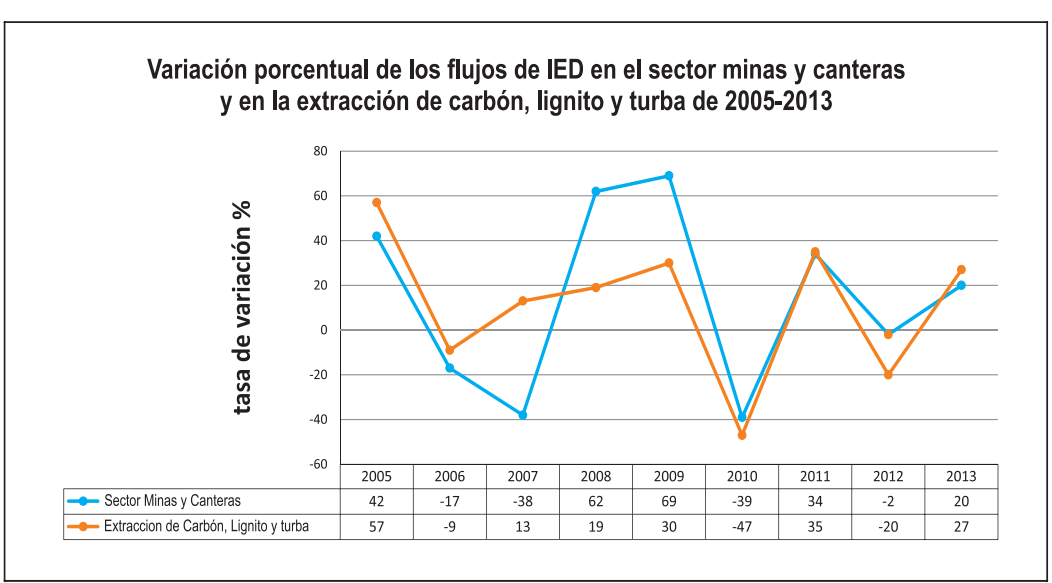

Figura 8. Variación porcentual de los fujos de IED en el sector minas y canteras y en la extracción de carbón, lignito y turba

Fuente: elaboración propia con datos oficiales del Banco de la República de Colombia y del Sistema de Información Minero Colombiano-SIMCO.
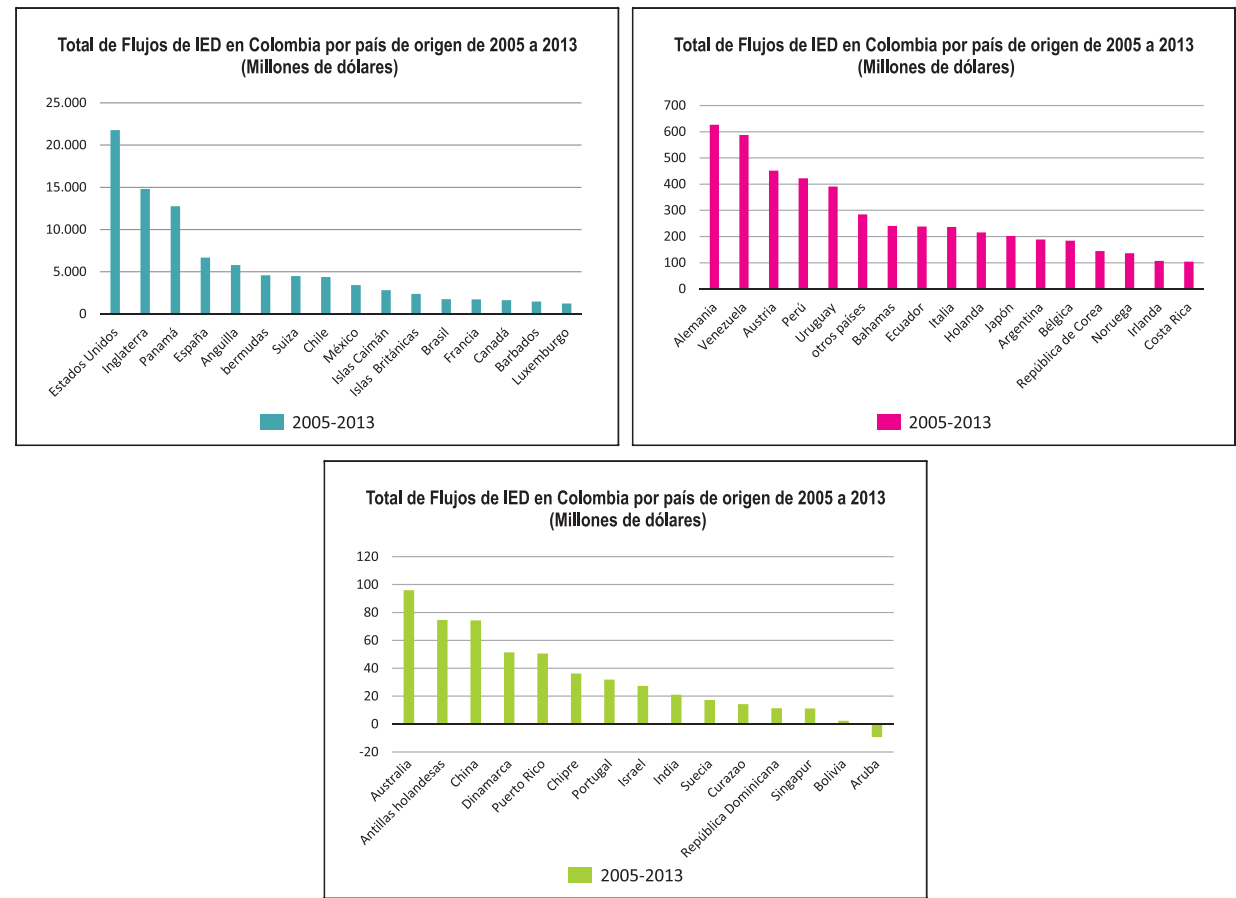

Figura 9. Total de Flujos de IED en Colombia por país de origen de 2005 a 2013 Fuente: elaboración propia con datos oficiales del Banco de la República de Colombia (2014). 
por encima de los \$US 1.000 millones. En orden descendente se encuentran: Estados Unidos, Inglaterra, Panamá, España, Anguila, Bermudas, Suiza, Chile, México, Islas Caimán, Islas Británicas, Brasil, Francia, Canadá, Barbados y Luxemburgo. El segundo grupo lo componen los países donde la suma total de IED en el periodo analizado se encuentra entre los 100 y los \$US 1.000 millones. En orden descendente se encuentran Alemania, Venezuela, Austria, Perú, Uruguay, Bahamas, Ecuador, Italia, Holanda, Japón, Argentina, Bélgica, República de Corea, Noruega, Irlanda y Costa Rica. El tercer grupo lo componen los países donde los montos de inversión están por debajo de los \$US 100 millones. En orden descendente se encuentran Australia, Antillas holandesas, China, Dinamarca, Puerto Rico, República de Chipre, Portugal, Israel, India, Suecia, Curazao, República Dominicana, Singapur y Bolivia.

\section{DISCUSIÓN}

De acuerdo con los resultados existen algunas reflexiones que se ponen en discusión para futuras investigaciones. La primera consiste en llamar la atención sobre la tendencia de concentración de los flujos de IED en los sectores primarios del país, lo cual ha sido posible gracias a los altos precios internacionales de los commodities y los incentivos otorgados por parte del Estado para atraer inversión foránea, sumado a las políticas que buscan promover al sector minero y petrolero como dos locomotoras del crecimiento económico del país.

Lo anterior resulta preocupante si no se logra identificar y caracterizar las modalidades de la inversión extranjera que ingresa al país. Es decir, es pertinente desagregar los montos de IED que ingresaron al país, en particular en los sectores analizados, con la intención de conocer, cuantificar, cualificar y caracterizar los aportes mismos de la inversión en términos de transferencias de tecnología, tipos de maquinarias aportadas, aportaciones al capital de la empresa, generación de empleos, etc., a fin de tener mayores conocimientos de causa a la hora de evaluar y determinar la contribución de la IED al desarrollo de dichos sectores y al mismo desarrollo y crecimiento económico del país. De lo contrario seguirán siendo cifras que pueden ocultar el verdadero propósito de la inversión y sus resultados. Si retomamos las discusiones de Elías et al. (1998), Carkovic y Levine (2002), Alfaro (2003), Loja y Torres (2013) y estructuralismo de la Cepal, encontramos que los beneficios de la IED con destino a los sectores primarios como el petróleo o la minería son casi nulos o negativos y pueden tener serias repercusiones, dadas las externalidades ambientales y el proceso de "descapitalización" y "desarticulación" de los proyectos.

Sin embargo, también es preciso aclarar que gracias a las particularidades 
del negocio minero, hay que tener precaución con los análisis sobre el crecimiento de la IED, debido a que el lapso requerido para materializar la inversión en exploración geológica con producción minera es de aproximadamente nueve años. Es decir, los recursos ingresados al país para gastos de funcionamiento y exploración serán retornados a las compañías casi un decenio después y solo si el proyecto logra superar los requerimientos técnicos, geológicos, ambientales, sociales, económicos y jurídicos necesarios para permitir la apertura de la mina. Por lo tanto, la IED no puede explicar por sí misma el aumento de la producción de un mineral ni de sus exportaciones a corto plazo, excepto cuando su destino específico es la adquisición de proyectos en producción, la expansión de operaciones o la apertura de la mina, luego de surtido el proceso de exploración (UPME, 2012). Por esta misma razón es pertinente desagregar y caracterizar los flujos de IED que han ingresado al sector minero, teniendo en cuenta las definiciones y las modalidades de IED existentes en el país o creando categorías para clasificar los aportes empíricos e inmateriales de la inversión.

En segundo lugar, existe la posibilidad de que los flujos de IED estén distribuidos en los departamentos y las regiones donde se concentra el mayor volumen de reservas, producción y exportación de carbón en Colombia. De lo anterior se conoce que en el año 2006 la IED dirigida al sector minero ascendió a
1.796 mUSD que incluye los $1.700 \mathrm{mi}-$ llones de la operación de compra del 33 $\%$ de Cerrejón a Glencore por parte de la compañía Xstrata (Portafolio, 2006). En las cifras de IED para 2009, el sector minero fue el mayor receptor de recursos con 3.014 mUSD, dentro de los que se incluyen dos mil millones por la venta de Prodeco en una operación que solo implicó el traspaso de la titularidad del yacimiento (Portafolio, 2009). En el mismo año, Vale aportó 373 millones de dólares en adquisiciones y 300 adicionales en reinversión (UPME, 2012). Para 2010 la IED fue de 1.838 mUSD, que incluyen la compra por parte de la compañía panameña Medoro (Gran Colombia Gold) de activos como: Frontino Gold Mines por 380 mUSD, Mineros Nacionales y Colombia Gold por valor de 50 millones de dólares. También se presentaron otras operaciones como la compra de la mina la Francia por el Grupo Goldman Sachs en 200 mUSD (Portafolio, 2009).

Como podemos observar, es pertinente desagregar y caracterizar los flujos de IED que ingresan al sector minero por país de origen y lugar destino. El análisis de la distribución geográfica de la IED en el territorio colombiano permitiría corroborar la hipótesis arriba mencionada, así como brindar información más detallada acerca de la contribución de la IED a nivel sectorial y regional, teniendo en cuenta los diferentes distritos mineros del país, así como las características propias de la población y los trabajadores en los 
lugares destino de la inversión. Lo anterior sería de utilidad para verificar de qué manera existe un beneficio directo o indirecto de la inversión extranjera, no solamente a nivel sectorial, sino también a nivel social y laboral, si tenemos en cuenta que la transferencia de conocimiento, de maquinaria y la generación de empleos son algunos de los posibles beneficios derivados de la inversión. Al respecto, vale mencionar que no existe un análisis de la distribución geográfica de la IED en el territorio nacional que desagregue los flujos de IED por sector económico, país y empresa de origen, lugar destino y modalidades de inversión.

En tercer lugar, se resalta la importancia de investigar acerca de las relaciones de la IED con el desarrollo sostenible del sector. Si uno de los beneficios de la IED es la transferencia de conocimiento, maquinaria y tecnología, tratándose de un sector de naturaleza primaria y extractiva como el carbón, es imprescindible analizar de qué manera dichas transferencias y contribuciones que provienen del exterior están enmarcadas en un mejor manejo de las externalidades negativas producto de la actividad minera y mejoran los esquemas productivos del sector, o si por el contrario, la concentración de la IED en los sectores primarios del país se debe a la falta de una regulación técnica y ambiental por parte de las autoridades pertinentes, lo cual sería desventajoso para el mismo desarrollo del sector y por supuesto para la población aledaña a los emprendimientos de explotación y transporte minero, así como a los trabajadores, el paisaje y el desarrollo sostenible de la nación.

\section{CONCLUSIONES}

El sector minero del carbón en Colombia presenta un verdadero potencial económico que se ve reflejado en las reservas y calidades de carbón, así como en su dinámica participación de exportaciones en el mercado internacional y su importante atracción de IED. En el periodo de 2004 a 2014 la IED presentó una concentración del $52 \%$ de los flujos totales de IED en los sectores primarios del petróleo (31\%) y la minería (21\%). Del total de IED que ingresó al sector minas, el $89 \%$ tuvo como destino la extracción de carbón, lignito y turba. Lo anterior fue posible gracias a los incentivos y las políticas económicas orientadas a captar y atraer mayores flujos de IED, y en especial, a las políticas orientadas a desarrollar a los sectores minero y petrolero como dos locomotoras del crecimiento económico del país. Sin embargo, existe una preocupación por la "primarización" de la IED que ingresó al país, debido al desconocimiento de información desagregada que permita poner bajo observación las modalidades en las que se realizaron las inversiones y la distribución geográfica de las mismas.

En este contexto se concluye, que si bien el sector minero del carbón representa un verdadero potencial para los 
inversionistas extranjeros, para el país es pertinente analizar de manera detenida cuáles han sido las modalidades que han tomado dichas inversiones, sobre todo en los sectores primarios. En los últimos años y debido a las reformas neoliberales, la IED ha pasado a tomar un espacio privilegiado en las políticas de desarrollo de los países en vías de desarrollo, bajo la expectativa de que la IED contribuya directa o indirectamente aumentando la producción y los empleos, así como también incrementando las capacidades del aprendizaje y la capacidad tecnológica. Para el caso analizado, el hecho de que la IED esté focalizada en la extracción de recursos mineros y petroleros disminuye las expectativas de los beneficios, mucho más cuando se desconoce con criterios rigurosos la manera como se han materializado dichas inversiones.

Por otra parte, así como se conoce la distribución geográfica tanto de las reservas como de las zonas de explotación y exportación de carbón en el país, también sería pertinente ubicar la distribución geográfica de la IED que ingresa al sector minero. Lo anterior permitiría verificar y conocer las rutas que toma la IED en el territorio nacional y sobre todo verificar los aportes empíricos de la inversión foránea en el sector de estudio. En este sentido, se concluye que el alcance de la investigación ha permitido identificar la evolución de los flujos de IED que han ingresado en el sector minero en un periodo determinado, pero ello no es suficiente para identificar y determinar los aportes y la contribución de la IED en el desarrollo el sector, dado que sería pertinente desagregar las cifras de IED, teniendo en cuenta las variables país de origen de la inversión, lugares mineros destino de la inversión y las modalidades que ha tomado dicha inversión, ya sea con relación a la generación de empleos, la transferencia de capitales, conocimientos o tecnologías.

\section{REFERENCIAS}

Agencia Nacional de Minería. (2014). Regalías y contraprestaciones económicas. Producción nacional de minerales. Serie de 2004 a 2013. Recuperado de http://www. anm.gov.co/?q=regalias-contraprestaciones-economicas

Alfaro, L. (2003). Foreign direct investment and growth: does the sector matter? Boston: Harvard Business School. Recuperado de http://www.grips.ac.jp/teacher/oono/hp/ docu01/paper14.pdf

Banco de la República de Colombia. (2014). Estadísticas, flujos de inversión directa según actividad económica y país de origen, anual desde 1994 y trimestral desde 1696. Recuperado de http://www.banrep.gov.co/es/inversion-directa 
Banco de la República de Colombia. (2014i). Principales exportaciones y resto de exportaciones. Mensual desde 1970. Balanza comercial. Exportaciones totales FOB. Bogotá. Colombia. Recuperado de http://www.banrep.gov.co/es/balanza-comercial

Banco Mundial. (2014). Crecimiento del PIB porcentaje anual. Recuperado de http://datos.bancomundial.org/pais/colombia

Baracaldo, F., Garzón, P. \& Vásquez, H. (2001). Crecimiento económico y flujos de inversión extranjera directa. Universidad Externado de Colombia. Facultad de Economía. Recuperado de http://portal.uexternado.edu.co/pdf/1_facultadEconomia/ Publicaciones/DocumentosDeTrabajo/AnalisisDeseriesDeTiempoDelSecuestroEnColombia.pdf

Bernal, H. (2012). Inversión extranjera directa en Colombia en el siglo XX, énfasis en el sector petróleo. Tesis de doctorado. Universidad de los Andes. Recuperado de $\mathrm{http} / / \mathrm{mba}$.americaeconomia.com/sites/mba.americaeconomia.com/files/inversion_extranjera_directa_en_colombia_en_el_siglo_xx.pdf

Borensztein, E., De Gregorio, J. \& Lee, J-W. (1998). How does foreign direct investment affect economic growth? Journal of International Economics 45, 115-135.

Borja, A. (1958). Inversión extranjera directa y desarrollo: enfoques teóricos y debate contemporáneo. Recuperado de http://aleph.org.mx/jspui/bitstream/56789/5581/1/ DOCT2065069_ARTICULO_9.PDF

Bornschier, V. (1980). Multinational Corporations and Economic Growth: a Cross National Test of the Decapitalization Thesis. Journal of Development Economics, 7, 191-210.

Carkovic, M. \& Levine, R. (2002). Does foreign direct investment accelerate economic growth? University of Minnesota. Department of Finance. WorkingPaper. Recuperado de http://siteresources.worldbank.org/INTFR/Resources/fdi.pdf

Conferencia de Naciones Unidas sobre Comercio y Desarrollo UNCTAD. (2013, junio). Informe sobre las inversiones en el mundo, panorama general 2013. Las cadenas de valor mundiales: inversión y comercio para el desarrollo. Nueva York.

Congreso de la República de Colombia (1991). Ley 9 de 1991. Normas generales a las que deberá sujetarse el Gobierno nacional para regular los cambios internacionales y se adoptan medidas complementarias. Bogotá, Colombia: Imprenta Nacional.

Congreso de la República de Colombia (2001). Ley 658 de 2001, Código de Minas. Bogotá, Colombia: Imprenta Nacional. 
Análisis de la evolución de la inversión extranjera directa en el sector minero del carbón en Colombia de 2004 a 2013

Fabián Alfredo Plazas Díaz

Congreso de la República de Colombia (2005). Ley 963 del 8 de julio de 2005. Ley de estabilidad jurídica para los inversionistas en Colombia. Bogotá, Colombia: Imprenta Nacional.

Contraloría General de la República. (2013). Minería en Colombia, derechos, políticas públicas y gobernanza. Recuperado de http://www.contraloriagen. gov.co/documents/10136/182119332/Libro_mineria_sep3_2013.pdf/65bf77a0-8b0b-430a-9726-dad0e72639c6

Contraloría General de la República. (2013i). Minería en Colombia, institucionalidad y territorio, paradojas y conflicto. Recuperado de http://www.contraloriagen.gov. co/documents/10136/182119332/MineriaEnColombia-Vol2.pdf/6cc33e0c-29e94a65-8561-1215fa8d07a0

De Mello, L. (1999). Foreign direct investment led growth: evidence from time series and panel data. Oxford Economic, Papers 51, 133-151.

Decreto 1844 (2003). Modificación al régimen general de inversiones de capital del exterior en Colombia y de capital colombiano en el exterior. Bogotá, Colombia: Imprenta Nacional.

Decreto 2080 (2000). Régimen general de inversiones de capital del exterior en Colombia y de capital colombiano en el exterior. Colombia: Banco de la República.

Departamento de Planeación Nacional. (1991). Resolución 51 de 1991. Estatuto de Inversiones Internacionales. Colombia.

Departamento Nacional Estadístico DANE. (2014i). Producto interno bruto trimestral a precios corrientes. Grandes ramas de actividad económica. Series desestacionalizadas. Bogotá D.C. Colombia. Recuperado de http://www.dane.gov.co/

Departamento Nacional de Estadística DANE. (2014). Exportaciones colombianas por partidas arancelarias y países de destino. Bogotá, Colombia: Grupo Ventas Directas, Dirección de Difusión, Mercadeo y Cultura Estadística Dane.

Egger, P. Pfaffermayr, M. (2001). Distance, trade and IED: A Hausman- Taylor SUR approach. Barcelona, España: Centre for Economic Policy Research.

Elías S., Fernández M. \& Ferrari A. (2006). Inversión extranjera directa y crecimiento económico: un análisis empírico. Bahía Blanca, Argentina: Universidad Nacional del Sur, Departamento de Economía.

Fedesarrollo. (2007). Impacto de la inversión extranjera en Colombia: situación actual y perspectivas. Proyecto elaborado por Fedesarrollo para Proexport. Informe final. Bogotá, Colombia: Fedesarollo. 
Fondo Monetario Internacional. (1994). Manual de balanza de pagos. (5ta ed.). Párrafo 359-362. Recuperado de http://www.imf.org/external/pubs/ft/bopman/bopman.pdf

Garay, L. J. (2004). Estructura industrial e internacionalización 1967-1996 inversión extranjera en Colombia. Bogotá, Colombia. Recuperado de https://pwh.dnp.gov.co/ LinkClick.aspx?fileticket $=\mathrm{vZv5DgPA10o} \% 3 \mathrm{D} \&$ tabid $=1287$

Gaviria, A. \& Gutiérrez, J. (1993). Inversión extranjera y crecimiento económico. Departamento Nacional de Planificación. Unidad de Análisis Macroeconómico. Archivos de Macroeconomía. Colombia. Documento Recuperado de http://www.scielo.org.co/scielo.php?script $=$ sci_nlinks\&ref $=000120 \&$ pid $=$ S0 120-2596200900020000500018\&lng=en

Haber, S. (1997). Crecimiento económico e historia económica de América Latina. Una contribución a la crítica de la teoría de la dependencia. Stanford University Press. Economía: teoría y práctica. No. 8. Recuperado de http://www.izt.uam.mx/economiatyp/numeros/numeros/08/articulos_PDF/8_9_Crecimiento.pdf

Hirschman, A. (1958). The strategy of economic development. New Haven, USA: Yale University.

Krugman, P. (1998). The role of geography in development. En B. Pleskovic, J. Stiglitz. (Ed.) Annual World Bank Conference on Development economics. Washington: World Bank and Oxford University Press. Retrieved from http://siteresources.worldbank.org/DEC/Resources/84797-1251813753820/6415739-1251813951236/ krugman.pdf

Loja, L.C. \& Torres, O. N. (2013). La inversión extranjera directa en el Ecuador durante el periodo 1979-2011: análisis de su incidencia en el crecimiento económico. Ecuador: Facultad de Ciencias Económicas y Administrativas, Universidad de Cuenca. Recuperado de http://dspace.ucuenca.edu.ec/bitstream/123456789/4728/1/TESIS.pdf

Mankiw, G., Romer, D. \& Weil D. (1992). A contribution to the empirics of economic growth. The Quarterly Journal of Economics, 107(2), 407-437.

Ministerio de Minas y Energía (2012). Cadena del carbón. Bogotá, Colombia: Unidad de Planeación Minero Energética. Recuperado de http://www.simco.gov.co/LinkClick.aspx?fileticket=ghcA7YSxZko

O'Hearn, D. (1990). TNCs Intervening Mechanisms and Economic Growth in Ireland: a Longitudinal Test and Extension of the Bornschier Model. World Development, $18,417-429$.

Organización para la Cooperación Económica y el Desarrollo OCDE. (2011). Definición marco de la inversión extranjera directa (4 ed.). Recuperado de http://www. oecd-ilibrary.org/fr/finance-and-investment/ocde-definicion-marco-de-inversion-extranjera-directa/prefacio_9789264094475-1-es?site=fr 
Análisis de la evolución de la inversión extranjera directa en el sector minero del carbón en Colombia de 2004 a 2013

Fabián Alfredo Plazas Díaz

Portafolio. (2006, 2 de marzo). Glencore vende a Xstrata el 33 por ciento de El Cerrejón. Revista Portafolio. Recuperado de http://www.portafolio.co/archivo/documento/ MAM-1934641

Portafolio. (2009, 29 de enero). Xstrata comprará Prodeco por US\$2.000 millones, las dos firmas tienen participación en Glencore. Revista Portafolio. Recuperado de http:/www.portafolio.co/archivo/documento/CMS-4783698

Prebish, R. (1949). El desarrollo económico en la América Latina y sus principales problemas. Chile: ECLAC, Santiago de Chile.

Ramírez, C. (2011). Marco jurídico de la inversión extranjera directa en Colombia. Saber, Ciencia y Libertad, 6(1), 163-177.

Ramírez, C. \& Flórez, L. (2006). Apuntes de inversión extranjera directa: definiciones, tipología y casos de aplicación colombianos. Apuntes de Economía, (8).

Romer, P. (1986). Increasing Returns and Long-Run Growth. Journal of Political Economy, 77, $1002-1037$.

Romer, P. (1990). Endogenous Technological Change. Journal of Political Economy, 98, 571-5102.

Rubini, H. \& Naranjo, M. (1997). Ahorro, inversión, mercado de capitales y crecimiento económico. Cuestiones Económicas, 31, 33-86.

Rudas, G. (2013). Notas sobre el estado de la minería de carbón a gran escala en Colombia. Foro Nacional Ambiental. Friedrich Ebert Stiftung en Colombia. Recuperado de http://library.fes.de/pdf-files/bueros/kolumbien/10468.pdf

Sala-I-Martin, X. (1994). Apuntes de crecimiento económico. Barcelona, España: Antoni Bosch.

Singer, H. (1950). U.S. foreign investment in underdeveloped areas, the distribution of gains between investing and borrowing countries. American Economic Review, Papers and Proceedings (40).

Sistema de Información Minero Colombiano SIMCO. (2014). Inversión extranjera directa. Recuperado de http://www.simco.gov.co/simco/Estad\%C3\%ADsticas/Inversi $\%$ C3\%B3nExtranjera/tabid/124/Default.aspx

Solow, R. M. (1956). A Contribution to the Theory of Economic Growth. The Quarterly Journal of Economics, 70(1), 65-94.

Swan, T. W. (1956). Economic growth and capital accumulation. The Economic Record, 32(2), 334-361.

82 
Stoneman, C. (1975). Foreign Capital and Economic Growth. World Development, 3(1), 11-26.

Unidad de Planeación Minero Energética UPME (2010). Boletín estadístico de minas y energía; 1990-2010. Bogotá: Ministerio de Minas y Energía.

Unidad de Planeación Minero Energética UPME. (2005). Distritos mineros, exportaciones e infraestructura. Bogotá: Ministerio de Minas y Energía.

Unidad de Planeación Minero Energética UPME. (2012). Estudio de producción de coque y carbón metalúrgico, uso y comercialización. Bogotá: Ministerio de Minas y Energía.

Unidad de Planeación Minero Energética UPME. (2006). Plan Nacional de Desarrollo Minero, Colombia País Minero visión al año 2019. Bogotá: Subdirección de Planeación Minera, Ministerio de Minas y Energía.

Unidad de Planeación Minero Energética UPME. (2012). Plan Nacional de Desarrollo Minero, Sector Minero de Cara a la Sociedad. Bogotá: Subdirección de Planeación Minera. Ministerio de Minas y Energía.

Zhang, K. (2001). ¿Does foreign direct investment promote economic growth? Evidence from East Asia and Latin America. Contemporary Economic Policy, 19(2), 175185. 
